\title{
EFEKTIVITASS PELATIHAN SELF-TALK UNTUK MENINGKATKAN HARGA DIRI REIMAJA KORBAN BULLYING (Studi pada Siswa SIMP X Pasar Minggu)
}

\author{
Isnaeni Marhani \\ Universitas Tarumanagara \\ J1 Letjen S. Parman No 1, Grogol, Jakarta Barat \\ isnaenimarhani@gmail.com, 087841987874 \\ Riana Sahrani \\ Universitas Tarumanagara \\ J1 Letjen S. Parman No 1, Grogol, Jakarta Barat \\ rianas@fpsi.untar.ac.id, 08129446539 \\ Sesilia Monika \\ Universitas Tarumanagara \\ J1 Letjen S. Parman No 1, Grogol, Jakarta Barat \\ monika@fpsi.untar.ac.id, 0818251029
}

\begin{abstract}
Adolescents who are unable to adapt in school environments are more likely to get bullying from other, more dominant or more popular students. Bullying makes teenagers difficult to actualize themselves, concentrate on learning, always feel insecure, and have low self-esteem. Teenagers with low self-esteem will believe that what the bully says about him is true and start blaming himself for being weak, not beautiful, or useless. Low self-esteem can be increased one of them through self-talk techniques that aim to deny irrational thinking and encourage the emergence of healthy thinking by saying positive sentences. Bullying behavior by peers is still common in junior high school, so some students become more quiet, crying in school, avoiding bullying, asking to move classes, to choose to change schools. This research was conducted to find out the effectiveness of self-talk training to increase the self-esteem of bullying students in SMP X. This study used experimental design involving 10 participants aged 14 to 16 years. The researchers used the SelfEstimation tool developed by Utomo (2011) as a pre-test and post-test. Based on different test with paired sample t-test on gain score of self esteem obtained mean value $14.80(S D=3.271)$ and $t=7.020, p<0.01$. Thus, self-talk training is effective to increase the self-esteem of bullying teenagers.
\end{abstract}

Keywords: Self-Esteem, Bullying, Self-Talk

\section{PENDAHULUAN}

\section{A. Latar Belakang} asa remaja merupakan masa perkembangan transisi antara masa anak dan masa dewasa yang mencakup perubahan biologis, kognitif, dan sosioemosional. Pada masa remaja, terdapat dua perubahan penting, yaitu 
perubahan lingkungan dan perubahan yang bersifat internal, yaitu karakteristik di dalam diri remaja yang membuat remaja relatif lebih bergejolak dibandingkan dengan masa perkembangan lainnya. Salah satu tugas perkembangan pada masa remaja adalah mulai mencari identitas dirinya yang menurut Erikson (dalam Papalia, Olds, \& Feldman, 2009) berada pada tahapan identitas vs kekacauan identitas (identity vs identity confusion). Remaja harus menentukan pemahaman akan diri sendiri atau akan merasakan kekacauan peran. Pada tahapan perkembangan ini peran teman sebaya memiliki pengaruh yang besar terhadap remaja. Bersama teman sebaya remaja dapat bekerja sama, saling menolong, bertukar pikiran, belajar bersama dan bermain bersama. Dari teman sebaya, remaja mendapat umpan balik mengenai kemampuannya.

Pengaruh teman sebaya dapat bersikap positif maupun negatif. Salah satu pengaruh negatif teman sebaya khususnya saat berada di sekolah adalah perilaku bullying. Olweus (1994) mendefinisikan bullying sebagai perilaku agresi yang sengaja dan berulangkali dilakukan oleh seseorang atau sekelompok orang dari waktu ke waktu kepada seseorang yang tidak mudah membela dirinya. Adapun perilaku agresi yang terjadi di sekolah ini menurut Orpinas, Horne, dan Staniszewski (2003) dapat menciptakan lingkungan yang tidak kondusif bagi kegiatan pembelajaran sehingga berdampak pada aspek emosional, akademik dan ketidakadilan bagi siswa yang menjadi korban. Menurut Papalia et al. (2009), remaja yang berada dalam lingkup sekolah jika tidak mampu melakukan adaptasi cenderung akan mendapatkan perlakuan bullying dari siswa lain yang lebih dominan atau lebih populer. Fenomena bullying masih kerap terjadi di lingkungan sekolah, salah satunya di SMP X, Siswa yang menjadi korban bullying menjadi lebih pendiam, menyendiri, menangis di sekolah, memilih menghindari pelaku bullying dengan mencari jalan lain jika harus berpapasan, memilih tidak berlama-lama di kantin sekolah, meminta pindah kelas, hingga memilih pindah sekolah. Bullying merupakan masalah yang sebenarnya sudah lama dikenal di masyarakat luas khususnya dalam lingkup sekolah, namun sangat disayangkan sejumlah pihak seolah menganggap fenomena ini tidak perlu mendapat perhatian serius. Elias dan Zins (2007) mengemukakan baik orangtua maupun pihak sekolah cenderung memandang bullying sebagai hal yang wajar sebab merupakan bagian dari tahapan perkembangan anak dan remaja yang sering mengalami konflik dengan teman sebaya khususnya pada usia sekolah. Hal senada dikemukakan oleh Murphy (2009) bahwa permasalahan bullying sudah lama kurang mendapat perhatian serius karena sebagian besar orang dewasa memiliki persepsi bahwa bullying merupakan hal umum yang memang wajar dialami oleh anak-anak.

Menurut Guntur (2011) bullying terjadi berulangkali pada korban yang sama dengan reaksi yang berbeda-beda dari setiap korbannya. Pada korban perempuan umumnya hanya dapat mengeluh atau menangis kesal. Sedangkan pada korban laki-laki biasanya ada yang mengeluh, ada juga yang berusaha melawan walaupun tidak berdaya pada akhirnya. Sementara itu, dampak yang ditimbulkan dari perlakuan bullying sangat 
beragam. Sejiwa (2008) mengemukakan sejumlah dampak dari bullying diantaranya; korba akan mengalamim kesulitan mengaktualisasikan dirinya; tidak memberikan rasa aman dan nyaman; membuat siswa yang menjadi korban merasa takut dan terintimidasi; rendah diri serta tak berharga; sulit berkonsentrasi dalam belajar; tidak tergerak untuk bersosialisasi dengan lingkungannya; ada keengganan untuk bersekolah; menjadi pribadi yang tak percaya diri dan sulit berkomunikasi; sulit berpikir jernih sehingga prestasi akademisnya terancam merosot. Mungkin pula para korban bullying akan kehilangan rasa percaya diri kepada lingkungan yang banyak menyakiti dirinya. Hal ini dikarenakan remaja dengan harga diri rendah memiliki perasaan tidak suka terhadap dirinya dan meyakini bahwa orang di lingkungan sekitarnya juga tidak menyukai dirinya, sehingga muncul kecenderungan untuk menarik diri dari lingkungan (Heatherton \& Wyland, dalam Lopez \& Snyder, 2003). Remaja yang menarik diri dari lingkungan akan memiliki hambatan dalam pencarian identitas diri dan dapat tumbuh menjadi individu yang tidak mengenal dirinya, tidak mengetahui apa yang diinginkan, tidak dapat bertanggung jawab pada dirinya, serta tidak memiliki kemampuan mengambil keputusan.

Harga diri merupakan aspek yang sangat penting dalam proses perkembangan diri, karena dapat mempengaruhi pengalaman emosional, tingkah laku di kemudian hari, prestasi akademis, dan penyesuaian psikologis jangka panjang. Individu dengan harga diri yang tinggi memiliki pandangan yang sehat mengenai diri sendiri, melihat sebuah kesalahan dengan realistis dan tidak memandang terlalu negatif serta kritis terhadap kesalahan yang dibuat (Pope, McHale, \& Craighead, 1998). Hal ini bukan tanpa alasan, sebab Baron dan Branscombe (2012) mengutarakan bahwa individu dengan harga diri tinggi merupakan individu yang menyukai dirinya sendiri. Siswa dengan harga diri tinggi menurut Coopersmith (dalam Mruk, 2006) umumnya mempunyai prestasi yang baik di sekolah, karena memiliki rasa ingin tahu dan motivasi dalam mengerjakan tugastugas, yang pada saat dewasa akan berpengaruh pada karirnya. Individu dengan harga diri tinggi cenderung sehat secara psikologis, sehingga lingkungan sekitar pun lebih mampu menerimanya.

Harga diri sangat bergantung pada persepsi atau pola pikir yang dijalani. Harga diri yang rendah dipengaruhi oleh persepsi atas penilaian individu terhadap dirinya. Wright (dalam Reece, 2008) menjelaskan, remaja dengan harga diri rendah akan mempercayai bahwa yang dikatakan pelaku bullying tentang dirinya adalah benar dan mulai menyalahkan dirinya karena lemah, tidak rupawan, atau tidak berguna. Heatherton dan Wyland (dalam Lopez \& Snyder, 2003) menambahkan keadaan ini akan menimbulkan kebencian remaja pada dirinya, perasaan putus asa, merasa depresi bahkan sebagian di antaranya memiliki keinginan untuk bunuh diri. Pola pikir remaja yang yang belum tentu sepenuhnya benar ini dapat direkonstruksi menjadi lebih positif melalui self-talk sehingga remaja dapat lebih memiliki persepsi yang lebih baik terhadap dirinya. Menurut Buttler dan Ottens (dalam Dembo, 2004), hal ini didasarkan pada 
keyakinan bahwa segala hal yang dikatakan remaja kepada dirinya sendiri merupakan faktor penentu sikap, perasaan, emosi, dan perilakunya.

Self-talk merupakan suatu pembicaraan internal yang terstruktur, berasal dari dan ditujukan kepada diri sendiri sebagai bentuk gambaran pemikiran mengenai individu dan dunianya (Burnett, 1996) sebab seringkali self-talk seorang individu dipengaruhi oleh yang dikatakan orang-orang tentang dirinya (Burnett \& McCrindle, dalam Erford, 2015). Agar manfaat self-talk dapat diperoleh secara maksimal, individu dapat melakukan self-talk dengan berbagai jenis metode. Helmstetter (1982) menjabarkan lima metode penggunaan self-talk, yaitu: 1) silent talk, merupakan pembicaraan berupa dialog internal yang dilakukan tanpa bersuara; 2) self-speak, pembicaraan yang diucapkan secara sadar (dengan suara) kepada diri sendiri atau disampaikan kepada orang lain mengenai diri sendiri; 3) self-conversation, yakni self-talk yang dilakukan dengan membuat suatu percakapan (dengan atau tanpa suara) kepada diri sendiri; 4) self-write, yakni menuliskan kata per kata atau kalimat untuk diri sendiri berupa pernyatan spesifik dan dapat digunakan sebagai programming untuk memberikan instruksi kepada diri; dan 5) tape-talk, tindak lanjut dari self-write yang dilakukan dengan memajang self-talk yang telah ditulis individu, yang seringkali dapat bermanfaat sebagai self-reminder. Sebagai salah satu jenis cognitive therapy, penerapan self-talk melibatkan aktivitas proses mental untuk menyangkal pemikiran irasional dan mendorong munculnya pemikiran sehat dengan mengucapkan kalimat positif. Hackfort dan Schwenkmezger (dalam Hardy, 2006) menyatakan bahwa dengan melakukan selftalk, remaja dapat menafsirkan perasaan, persepsi, mengatur, mengubah, mengevaluasi keyakinan, serta memberikan dirinya instruksi dan penguatan. Penguatan ini dimaksudkan untuk melawan keyakinan irasional dan membantu dalam mengembangkan pikiran yang lebih sehat, yang akan membimbing pada self-talk yang lebih positif (Hidayat, 2011). Pola pikir yang sehat akan mempengaruhi tingginya harga diri, sebab melalui self-talk positif remaja akan memandang dirinya dari sisi yang positif pula. Self-talk dapat digunakan remaja untuk membantu mengontrol kecemasan, suasana hati, dan respon emosional lainnya. Self-talk juga dapat digunakan untuk mengatasi perfeksionisme, meregulasi emosi, dan meningkatkan harga diri. Harga diri merupakan aspek yang sangat penting dalam proses perkembangan diri remaja, karena dapat mempengaruhi pengalaman emosional, tingkah laku di kemudian hari, prestasi akademis, dan penyesuaian psikologisnya untuk jangka panjang.

\section{B. Metode Penelitian}

Desain penelitian yang digunakan experimental dengan tipe pretest-posttest control group design. Perlakuan eksperimen yang diberikan pada penelitian ini adalah intervensi berupa pelatihan self-talk kepada kelompok eksperimen, sedangkan kelompok kontrol tidak mendapatkan informasi atau perlakuan apapun. Dalam penelitian ini, peneliti ingin mengetahui efektivitas pelatihan self-talk terhadap harga diri para siswa korban bullying sebelum dan sesudah mendapatkan perlakuan. Untuk 
mengetahui efektivitas pelatihan self-talk terhadap peningkatan harga diri pada siswa korban bullying, dapat dilihat melalui gain score antara pre-test dan post-test pada kelompok kontrol dan kelompok eksperimen. Sementara dalam menentukan partisipan, peneliti menggunakan teknik nonprobability sampling dengan metode purposive sampling, yaitu metode pengambilan sampel secara sengaja sesuai dengan karakteristik sampel yang diperlukan. Adapun karakteristik partisipan pelitian ini adalah (a) sedang menempuh pendidikan di SMP X, (b) berusia 13 hingga 16 tahun, (c) mengalami sekurang-kurangnya dua kali perlakuan bullying dalam satu minggu khususnya di lingkungan sekolah, dan (d) memiliki harga diri yang tergolong kategori rendah berdasarkan alat ukur Harga Diri yang disusun oleh Utomo (2011) dan. Peneliti tidak membatasi karakteristik partisipan berdasarkan jenis kelamin, agama, status ekonomi, maupun status sosial. Berdasarkan kriteria tersebut, maka terdapat lima partisipan yang terlibat dalam penelitian ini.

Tabel 1. Identitas Partisipan Kelompok Eksperimen

\begin{tabular}{|c|c|c|c|c|c|c|}
\hline \multirow{2}{*}{\multicolumn{2}{|c|}{ Keterangan }} & \multicolumn{5}{|c|}{ Partisipan } \\
\hline & & DV & IL & IN & MT & SD \\
\hline \multicolumn{2}{|c|}{ Jenis kelamin } & Perempuan & Laki-laki & Perempuan & Perempuan & Perempuan \\
\hline \multirow{2}{*}{\multicolumn{2}{|c|}{ Usia }} & 14 tahun & 14 tahun & 16 tahun & 15 tahun & 14 tahun \\
\hline & & 7 bulan & 10 bulan & 1 bulan & 2 bulan & 8 bulan \\
\hline \multicolumn{2}{|c|}{$\begin{array}{l}\text { Urutan dalam } \\
\text { keluarga }\end{array}$} & 1 dari 3 & 1 dari 3 & 4 dari 4 & 2 dari 5 & 3 dari 3 \\
\hline \multicolumn{2}{|c|}{ Agama } & Islam & Islam & Islam & Islam & Islam \\
\hline \multicolumn{2}{|c|}{ Berat badan } & $70 \mathrm{~kg}$ & $36 \mathrm{~kg}$ & $43 \mathrm{~kg}$ & $72 \mathrm{~kg}$ & $51 \mathrm{~kg}$ \\
\hline \multicolumn{2}{|c|}{ Tinggi badan } & $153 \mathrm{~cm}$ & $140 \mathrm{~cm}$ & $153 \mathrm{~cm}$ & $153 \mathrm{~cm}$ & $153 \mathrm{~cm}$ \\
\hline \multirow{2}{*}{ Suku } & Ayah & Betawi & Betawi & Sunda & Sunda & Batak \\
\hline & Ibu & Jawa & Betawi & Betawi & Sunda & Batak \\
\hline \multirow{2}{*}{ Pekerjaan } & Ayah & $\begin{array}{l}\text { Peg. } \\
\text { swasta }\end{array}$ & Montir & Ojek & Pedagang & Pedagang \\
\hline & Ibu & $\begin{array}{l}\text { Peg. } \\
\text { swasta }\end{array}$ & IRT & IRT & IRT & IRT \\
\hline \multicolumn{2}{|c|}{$\begin{array}{c}\text { Jenis bullying yang } \\
\text { dialami }\end{array}$} & $\begin{array}{l}\text { Sosial, } \\
\text { Verbal, }\end{array}$ & $\begin{array}{l}\text { Fisik, } \\
\text { Sosial, }\end{array}$ & $\begin{array}{l}\text { Fisik, } \\
\text { Sosial, }\end{array}$ & $\begin{array}{l}\text { Fisik, } \\
\text { Sosial, }\end{array}$ & $\begin{array}{l}\text { Fisik, } \\
\text { Sosial, }\end{array}$ \\
\hline
\end{tabular}


Elektronik Verbal, Verbal, Verbal, Verbal, Elektronik Elektronik Elektronik Elektronik

Seluruh proses pengambilan data dan intervensi dilakukan di SMP X. Adapun variabel harga diri pada penelitian ini diukur menggunakan alat ukur Harga Diri yang disusun oleh Utomo (2011), di mana semakin tinggi skor atau nilai pada alat ukur ini, menunjukkan bahwa semakin baik evaluasi dan penilaian partisipan terhadap dirinya sendiri. Alat ukur Harga Diri ini juga akan digunakan sebagai post-test yang akan diberikan kepada partisipan setelah mendapat intervensi.

\section{Pelaksanaan intervensi}

Intervensi pelatihan self-talk dilakukan sebanyak 9 sesi melalui metode ceramah, diskusi, role play, relaksasi, dan pemberian tugas. Tahapan sesi intervensi pelatihan self-talk yang diberikan menggunakan lima tahap dari Young (2017) yaitu: (a) Tahap pertama, diadakan sebanyak 2 sesi. Partisipan diberi pemaparan mengenai definisi bullying dan self-talk. Di akhir sesi ini partisipan diberikan tugas melakukan selfmonitoring selama satu pekan. Tugas ini berupa index card berjumlah 30 lembar yang wajib dibawa oleh partisipan kemanapun dan menuliskan segala self-talk negatif yang muncul berkaitan dengan dampak bullying yang mereka alami. Partisipan diingatkan membawa index card tersebut pada sesi selanjutnya; (b) Tahap kedua, diadakan sebanyak 2 sesi. Pada tahap ini partisipan diminta untuk mengidentifikasi tiga self-talk negatif dari tugas self-monitoring kemudian mempaktikkan dua dari metode self-talk yakni silent talk dan self-speak; (c) Tahap ketiga, diadakan sebanyak 2 sesi. Partisipan diminta untuk mengidentifikasi counter statement yang efektif untuk menentang selftalk negatif kemudian mempraktikkan metode self-conversation talk; (d) Tahap keempat, diadakan sebanyak 2 sesi. Partisipan diminta menguji efektivitas counter statement yang dipilih menggunakan subjective unit distress scale (SUDS) kemudian mempraktikkan metode self-write dan tape-talk; dan (e) Tahap kelima, diadakan 1 sesi. Pada sesi ini partisipan diminta melakukan evaluasi terhadap counter statement yang telah diterapkan kemudian ditutup dengan pelaksanaan post-test.

\section{PEMBAHASAN}

Setelah seluruh rangkaian sesi intervensi pelatihan self-talk dilaksanakan, dilakukan post-test terhadap kelompok eksperimen dan kelompok kontrol. Berikut ini disajikan data hasil post-test serta gain score atau selisih skor pre-test dan post-test dari kedua kelompok.

Tabel 2. Perbandingan skor pre-test dan post-test kelompok eksperimen

\begin{tabular}{ccccc}
\hline Nama & Jenis Kelamin & Skor pre-test & Skor post-test & Gain score \\
\hline MT & Perempuan & 52,00 & 70,00 & 18,00 \\
DV & Perempuan & 54,00 & 67,00 & 13,00 \\
IN & Perempuan & 57,00 & 74,00 & 17,00 \\
\hline
\end{tabular}




\begin{tabular}{ccccc}
\hline IL & Laki-laki & 59,00 & 69,00 & 10,00 \\
SD & Perempuan & 61,00 & 77,00 & 16,00 \\
\hline
\end{tabular}

Tabel 3. Perbandingan skor pre-test dan post-test kelompok kontrol

\begin{tabular}{ccccc}
\hline Nama & Jenis Kelamin & Skor pre-test & Skor post-test & Gain score \\
\hline PU & Perempuan & 52,00 & 57,00 & 5,00 \\
YS & Laki-laki & 52,00 & 56,00 & 4,00 \\
HF & Laki-laki & 55,00 & 59,00 & 4,00 \\
BL & Perempuan & 56,00 & 61,00 & 5,00 \\
SB & Perempuan & 61,00 & 64,00 & 3,00 \\
\hline
\end{tabular}

Berdasarkan data hasil post-test di atas diketahui bahwa hasil nilai pre-test harga diri pada kelompok eksperimen lebih rendah dari nilai post-test. Dengan demikian dapat disimpulkan bahwa terjadi peningkatan harga diri pada siswa yang mengalami bullying setelah mendapat pelatihan self-talk. Selain itu dapat dilihat juga berdasarkan data hasil post-test di atas diketahui bahwa hasil nilai pre-test harga diri kelompok kontrol lebih rendah dari nilai post-test.

Sebelum dilakukan uji beda antara skor pre-test dan post-test pada kelua kelompok, maka dilakukan uji normalitas terlebih dahulu untuk mengetahui sebaran normalitas data yang diperoleh dengan menggunakan 1-sample KS pada SPSS versi 15 . Berdasarkan uji normalitas diketahui bahwa sebaran data mean harga diri dari alat ukur Harga Diri pre-test dan alat ukur Haga Diri post-test terdistribusi normal. Nilai p untuk mean harga diri pre-test yaitu $\mathrm{p}=0.949$ ( $\mathrm{p}>0.05)$ dengan hasil Kolmogorov-Smirnov $=$ 0.520 , sedangkan nilai $\mathrm{p}$ untuk mean harga diri post-test yaitu $\mathrm{p}=0.996(\mathrm{p}>0.05)$ dengan hasil Kolmogorov-Smirnov $=0.409$.

Oleh karena sebaran data yang diperoleh terdistribusi normal, maka selanjutnya digunakan uji beda dengan parametrik paired sample t-test, dan diperoleh $\mathrm{t}=-4.988$ dengan $\mathrm{p}=0.001(\mathrm{p}<0.01)$ artinya terdapat perbedaan sebelum dan sesudah intervensi dilakukan.

Setelah dilakukan uji beda pada kedua kelompok secara keseluruhan, pengujian kembali dilakukan untuk mengetahui perbedaan hasil masing-masing kelompok. Setelah dilakukan uji beda pada kelompok eksperimen dengan menggunakan teknik paired sample t-test untuk aspek harga diri, diperoleh nilai mean pada pre-test kelompok eksperimen adalah 56.60 ( $\mathrm{SD}=3.646)$, sedangkan niai mean pada post-test kelompok eksperimen adalah 71.40 ( $\mathrm{SD}=4.037)$. Selanjutnya dari hasil uji perbedaan, diperoleh nilai $\mathrm{t}=-10.117, \mathrm{p}=0.001<0.05$, dengan demikian terdapat perbedaan harga diri yang signifikan baik pada pre-test dan post-test pada kelompok eksperimen.

Sedangkan setelah dilakukan uji beda pada kelompok kontrol dengan menggunakan teknik paired sample t-test untuk aspek harga diri, diperoleh nilai mean pada pre-test kelompok kontrol adalah 55.20 ( $\mathrm{SD}=3.701$ ), sedangkan niai mean pada post-test kelompok kontrol adalah 59.40 ( $\mathrm{SD}=3.209)$. Selanjutnya dari hasil uji 
perbedaan, diperoleh nilai $\mathrm{t}=-11.225, \mathrm{p}=0.000<0.05$, dengan demikian terdapat perbedaan harga diri yang signifikan baik pada pre-test dan post-test pada kelompok kontrol.

Adapun untuk mengetahui perbedaan efektivitas dari pelatihan self-talk yang dilakukan kepada kelompok eksperimen serta kepada kelompok kontrol yang tidak diberi informasi atau perlakuan apapun, akan dilakukan uji beda berdasarkan gain score kelompok eksperimen dan kelompok kontrol.

Tabel 4. Hasil uji beda paired sample t-test gain score

\begin{tabular}{llccc}
\hline \multirow{3}{*}{ Gain Score } & Kelompok & Mean & Std.Dev & T \\
& Eksperimen & 14.80 & 3.271 & 7.020 \\
\hline
\end{tabular}

Berdasarkan tabel uji beda dengan paired sample t-test pada gain score diperoleh nilai mean pada kelompok eksperimen sebesar 14.80 ( $\mathrm{SD}=3.271)$, sedangkan nilai mean pada kelompok kontrol sebesar 4.20 ( $\mathrm{SD}=0.836$ ), sehingga dapat disimpulkan kedua kelompok mengalami kenaikan skor harga diri baik pada kelompok eksperimen yang mendapat pelatihan self-talk maupun kelompok kontrol yang tidak mendapat informasi atau perlakuan apapun. Dapat dilihat juga kelompok eksperimen mengalami kenaikan yang lebih tinggi 14.80 ( $\mathrm{SD}=3.271$ ) dibanding kelompok kontrol 4.20 ( $\mathrm{SD}=0.836)$. Selain itu, dari hasil uji perbedaan diperoleh nilai $t=7.020, \mathrm{p}<0.01$, dengan demikian dapat disimpulkan bahwa kelompok eksperimen memiliki perubahan yang signifikan dibanding dengan kelompok kontrol. Oleh karenanya dapat disimpulkan bahwa intervensi pelatihan self-talk dapat meningkatkan harga diri pada kelima partisipan siswa SMP X yang menjadi korban bullying.

\section{KESIMPULAN}

Penelitian ini bertujuan untuk menguji efektivitas intervensi berupa pelatihan selftalk dalam meningkatkan harga diri siswa korban bullying. Partisipan dalam penelitian ini berjumlah 10 orang yang terdiri dari masing-masing lima partisipan untuk kelompok eksperimen dan kelompok kontrol. Pada kelompok eksperimen mendapatkan intervensi berupa pelatihan self-talk, sedangkan kelompok kontrol tidak mendapatkan informasi atau perlakuan apapun. Pengolahan data pada penelitian ini yang menggunakan uji statistik paired sample t-test menunjukkan terdapat perbedaan pada hasil pre-test dan post-test kedua kelompok.

Sebelum dilakukan uji beda antara skor pre-test dan post-test pada kelua kelompok, maka dilakukan uji normalitas terlebih dahulu untuk mengetahui sebaran normalitas data yang diperoleh dengan menggunakan 1-sample KS pada SPSS versi 15 . Berdasarkan uji normalitas diketahui bahwa sebaran data mean harga diri dari alat ukur Harga Diri pre-test dan alat ukur Haga Diri post-test terdistribusi normal. Nilai p untuk mean harga diri pre-test yaitu $\mathrm{p}=0.949$ ( $\mathrm{p}>0.05)$ dengan hasil Kolmogorov-Smirnov $=$ 
0.520, sedangkan nilai $\mathrm{p}$ untuk mean harga diri post-test yaitu $\mathrm{p}=0.996(\mathrm{p}>0.05)$ dengan hasil Kolmogorov-Smirnov $=0.409$. Oleh karena sebaran data yang diperoleh terdistribusi normal, maka selanjutnya digunakan uji beda dengan parametrik paired sample t-test. Berdasarkan tabel uji beda dengan paired sample t-test diperoleh $\mathrm{t}=$ 4.988 dengan $\mathrm{p}=0.001(\mathrm{p}<0.01)$ artinya terdapat perbedaan sebelum dan sesudah intervensi dilakukan.

Setelah dilakukan uji beda pada kedua kelompok secara keseluruhan. Pengujian kembali dilakukan untuk mengetahui perbedaan hasil masing-masing kelompok. Setelah dilakukan uji beda pada kelompok eksperimen dengan menggunakan teknik paired sample t-test untuk aspek harga diri, diperoleh nilai mean pada pre-test kelompok eksperimen adalah 56.60 ( $\mathrm{SD}=3.646)$, sedangkan niai mean pada post-test kelompok eksperimen adalah 71.40 ( $\mathrm{SD}=4.037)$. Selanjutnya dari hasil uji perbedaan, diperoleh nilai $\mathrm{t}=-10.117, \mathrm{p}=0.001<0.05$, dengan demikian terdapat perbedaan harga diri yang signifikan baik pada pre-test dan post-test pada kelompok eksperimen.

Sedangkan setelah dilakukan uji beda pada kelompok kontrol dengan menggunakan teknik paired sample t-test untuk aspek harga diri, diperoleh nilai mean pada pre-test kelompok kontrol adalah 55.20 ( $\mathrm{SD}=3.701$ ), sedangkan niai mean pada post-test kelompok kontrol adalah 59.40 ( $\mathrm{SD}=3.209)$. Selanjutnya dari hasil uji perbedaan, diperoleh nilai $\mathrm{t}=-11.225, \mathrm{p}=0.000<0.05$, dengan demikian terdapat perbedaan harga diri yang signifikan baik pada pre-test dan post-test pada kelompok kontrol. Adapun untuk mengetahui perbedaan efektivitas dari pelatihan self-talk yang dilakukan kepada kelompok eksperimen serta kepada kelompok kontrol yang tidak diberi informasi atau perlakuan apapun, akan dilakukan uji beda berdasarkan gain score kelompok eksperimen dan kelompok kontrol.

Berdasarkan hasil uji beda dengan paired sample t-test pada gain score kelompok eksperimen diperoleh nilai mean 14.80 ( $\mathrm{SD}=3.271)$ dan 4.20 ( $\mathrm{SD}=0.836)$ pada kelompok kontrol, sehingga dapat disimpulkan kedua kelompok mengalami peningkatan harga diri. Dapat dilihat juga kelompok eksperimen mengalami kenaikan yang lebih tinggi 14.80 ( $\mathrm{SD}=3.271$ ) dibanding kelompok kontrol 4.20 ( $\mathrm{SD}=0.836)$. Selain itu, dari hasil uji perbedaan diperoleh nilai $\mathrm{t}=7.020, \mathrm{p}<0.01$, dengan demikian dapat disimpulkan bahwa kelompok eksperimen memiliki perubahan yang signifikan dibanding dengan kelompok kontrol. Oleh karenanya dapat disimpulkan bahwa intervensi pelatihan self-talk dapat meningkatkan harga diri pada kelima partisipan siswa SMP yang menjadi korban bullying.

\section{SARAN}

Berdasarkan uraian di atas, peneliti memberikan beberapa saran kepada peneliti selanjutnya. Pertama adalah agar peneliti selanjutnya membandingkan antara efektivitas pelatihan self-talk menggunakan kelima metode yakni metode silent-talk, self-speak, self-conversation, self-write, dan tape-talk. Pada penelitian ini kelima metode tersebut 
hanya digunakan untuk mengenalkan berbagai teknik dalam melakukan self-talk namun tidak bertujuan untuk membandingkan efektivitas penggunaan salah satu metode tersebut. Saran kedua agar peneliti selanjutnya dapat membandingkan antara efektivitas pelatihan self-talk yang dilakukan pada karakteristik berbeda. Partisipan pada penelitian selanjutnya diharapkan tidak hanya melibatkan usia remaja, namun disarankan meneliti pada tahapan perkembangan berbeda seperti pada usia anak atau dewasa. Selain itu, karakteristik berbeda juga disarankan pada partisipan laki-laki dan perempuan.

Penelitian dengan membandingkan penerapan self-talk pada jenis kelamin berbeda ini diharapkan dapat menunjukkan perbedaan efektivitas self-talk jika ditinjau dari jenis kelamin yang berbeda. Saran ketiga melakukan pengontrolan kepada partisipan kelompok eksperimen yang diberikan perlakuan agar tidak menyampaikan informasi apapun kepada kelompok kontrol mengenai perlakuan atau pelatihan yang diberikan. Peneliti memiliki keterbatasan dalam melakukan pengontrolan kepada partisipan kelompok eksperimen yang sekelas dengan partisipan kelompok kontrol. Partisipan kelompok eksperimen berperan dalam memberikan informasi kepada kelompok kontrol mengenai pelatihan self-talk yang mereka dapatkan, sehingga peneliti selanjutnya diharapkan melibatkan partisipan dari kelas atau sekolah berbeda sebagai salah satu variasi yang diperhitungkan dalam pemberian intervensi. Saran kelima adalah agar peneliti selanjutnya dapat melibatkan salah seorang guru dari sekolah yang mejadi tempat penelitian dalam pelaksanaan intervensi. Guru dapat menjadi agent of change yang dapat melanjutkan pelaksanaan intervensi jika dirasa bermanfaat oleh pihak sekolah.

Saran kepada orangtua agar mengajarkan teknik self-talk untuk mendorong anak melawan keyakinan irasional terhadap segala hal yang diucapkan atau dilakukan pelaku bullying saat di sekolah dan menggantinya dengan pikiran yang lebih sehat. Pola pikir yang sehat akan mempengaruhi tingginya harga diri anak, sebab melalui self-talk positif anak akan memandang dirinya dari sisi yang positif pula. Orangtua yang membiasakan anak melakukan self-talk positif akan meningkatkan harga diri anak sehingga anak akan mempunyai prestasi yang lebih baik di sekolah, karena memiliki rasa ingin tahu dan motivasi dalam mengerjakan tugas-tugas sehingga pada saat dewasa akan berpengaruh pada karirnya. Orangtua juga disarankan menerapkan pola asuh yang mengajarkan perilaku saling menghargai dan menghormati sejak dini. Hal terkecil dapat dimulai dengan menghargai hak anak ataupun perbedaan sesama saudara serta keluarga terdekat di lingkungan rumah. Dengan membiasakan anak saling menghargai akan berdampak positif pada kemampuan beradaptasi anak jika dihadapkan pada lingkungan baru di manapun berada.

Saran kepada pihak sekolah, terutama melalui guru dapat mempertimbangan untuk mengadakan pelatihan self-talk kepada siswa yang mengalami bullying namun belum dilibatkan pada penelitian ini. Self-talk dapat menjadi salah satu cara mendorong siswa melawan keyakinan irasional dan membantu dalam mengembangkan pikiran yang 
lebih sehat. Di samping itu melalui bimbingan guru khususnya bidang bimbingan dan konseling, self-talk juga dapat dilakukan oleh siswa yang mengalami bullying untuk mengontrol kecemasan, suasana hati, dan berbagai respon emosi negatif lainnya yang mempengaruhi perilaku siswa di sekolah seperti membolos, menyendiri, dan menghindari siswa pelaku bullying.

\section{DAFTAR PUSTAKA}

Baron, R. A., \& Branscombe, Nyla, R. (2012). Social psychology (13 ${ }^{\text {th }}$ ed.). New Jersey, NJ: Pearson Education, Inc.

Burnett, P. C. (1996). Children's self-talk and significant others' positive and negative statements. Educational Psychology, 16, 57-67.

Dembo, M. H. (2004). Motivation and learning strategies for college success (A selfmanagement approach) ( $2^{\text {nd }}$ ed.). Mahwah, NJ: Lawrence Erlbaum Associate Publisher.

Elias, M. J., \& Zins, J. E. (2007). Bullying, victimization, and peer harassment: A handbook of prevention and intervention. New York, NY: Haworth Press.

Erford, B. T. (2015). 40 techniques every counselor should know ( $2^{\text {nd }}$ ed.). New Jersey, NJ: Pearson Education, Inc.

Guntur, I. (2011). Intervensi antibullying_163 berbasis experiental learning terhadap remaja yang melakukan bullying di sma $c$ (Tesis tidak diterbitkan). Universitas Tarumanagara, Jakarta.

Hardy, J. (2006). Speaking clearly: A critical review of the self-talk literature. Psychology of Sport and Exercise, 7, 81-97.

Helmstetter, S. (1982). What to say when you talk to your self. New York, NY; Pocket Books.

Hidayat, Y. (2011). Review self-talk: Konsep, dimensi, dan perspektif teori (Tesis tidak diterbitkan). Universitas Pendidikan Indonesia, Bandung.

Lopez, S. J., \& Snyder C. R. (2003). Positive psychological assessment: A handbook of models and measures. Washington, DC: American Psychological Association.

Mruk, C. J. (2006). Self-esteem research, theory, and practice: Toward a positive psychology of self-esteem ( $3^{\text {rd }}$ ed.). New York, NY: Springer Publishing Co.

Murphy, A. G. (2009). Character education: Dealing with bullying. New York, NY: Chelsea House. 
Olweus, D. (1994). Bullying at shool; basic facts and effects of a school based intervention program. Journal of child psychology and psychiatry, 35(7), 11711190.

Orpinas, P, Horne, A. M. (2006). Bullying prevention: Creating a positive school climate and developing social competence. Washington, DC: American Psyhological Association.

Papalia, D. E., Olds, S. W., \& Feldman, R. D. (2009). Human development (11 $1^{\text {th }}$ ed.). New York, NY: McGraw Hill.

Pope, A. W., McHale, S. M., \& Craighead, W. E. (1998). Self-esteem enhancement with children and adolescents. Boston, MA: Allyn and Bacon.

Reece, T. (2008). Beating down self-esteem. New Jersey, NJ: John Wiley \& Sons.

Sejiwa (Tim Yayasan Semai Jiwa Amini). 2008. Bullying: Mengatasi kekerasan di sekolah dan lingkungan sekitar anak. Jakarta: Grasindo.

Utomo, E., T. (2011). Efektivitas rational emotive behavior therapy untuk meningkatkan harga diri remaja putri yang tinggal di panti asuhan (Tesis tidak diterbitkan). Universitas Tarumanagara, Jakarta.

Young, M. E. (2017). Learning the art of helping: Building blocks and techniques (6 $^{\text {th }}$ ed.). Boston, MA: Pearson. 